\title{
SPRAYCAST- $X^{\circledR}$ IN718 PROCESSING BENEFITS
}

\author{
Neil Paton, Tony Cabral ${ }^{\star}$, Kim Bowen, Thomas Tom \\ Howmet Corporation \\ 1500 South Warner Street \\ Whitehall, Ml 49461 \\ *United Technologies/Pratt \& Whitney \\ 400 Main Street \\ East Hartford, CT 06108
}

\begin{abstract}
The Spraycast- $X^{\circledR}$ process has been developed by Howmet, and verified on a wide range of nickel-base superalloys, including IN718, for manufacturing thick wall ( 3 ") structures for jet engine rings and cases. This process yields a material and product that is clean and eliminates ring rolling. Other features of the product produced by the Spraycast- $X^{\circledR}$ process are its fine homogeneous microstructure, improved machinability, and ability to process previously non-forgeable alloys. The Spraycast- $X^{\circledR}$ process results in lead-time reductions of up to $75 \%$ over ring rolled components. This process is capable of manufacturing parts that may be used in the spray + HIP form, as a replacement for ring rolling, with equivalent or improved mechanical properties. Rapid prototyping of parts is a Spraycast- $X^{\circledR}$ attribute, due to the rapid turn time of the process and its inexpensive tooling. Apart from the technical and delivery benefits of the Spraycast- $X^{\circledR}$ process, there are economic benefits that indicate savings of up to $30 \%$ over its ring rolled counterpart. A description of the process, along with data which substantiate these claims, will be presented.
\end{abstract}

\section{Introduction}

Spray deposition techniques have many potential advantages, not the least of which is the opportunity to produce near net shape products at high solidification rates. Near net shape manufacturing methods are attractive because they have the potential to produce components at very low cost while the high effective cooling rate obtainable with spray forming is attractive because very fine grain size structures can be obtained with minimum segregation. These advantages were first recognized in the 1970's by a group working out of the University College of Swansea in the United Kingdom ${ }^{(1)}$, but despite significant efforts by a number of groups since that time, spray forming has achieved only a limited amount of interest from industry due to many factors.

\footnotetext{
Superalloys $718,625,706$ and Various Derivatives Edited by E.A. Loria

The Minerals, Metals \& Materials Society, 1997
} 
The difficulty of controlling the process is probably principle among the reasons why spray forming has not been more broadly applied in industry. There are numerous other technical difficulties which have slowed the rate of application of this interesting technology. Examples of these difficulties are: gas entrapment, oxidation, reaction of the molten metals spray with the gas used for atomization, and fissure porosity, particularly on the inside diameter of tubular shape products

Over a period of some years, Howmet has embarked upon an intensive program to find solutions to these processing difficulties and has worked with several potential customers (including Pratt \& Whitney) to evaluate and solve these problems. Over the last two years, significant progress has been made toward making the spray forming process a production reality on advanced nickel base superalloys such as INCONEL 718; and the process is now at the point where developmental product is being produced for evaluation.

The principle advantage of directly spraying a preform, and hot isostatically pressing this preform to achieve consolidation, is that the number of processing steps are reduced which reduces lead-time to produce a shape. By using this truncated processing routine, the process has potential benefit for use as a rapid prototyping route and, on occasion, preforms have been produced to a customer's drawing within two weeks of receipt of the product definition. This compares to typically many months to go through the standard pierced billet and ring rolling approach currently used by the aerospace industry.

As a result of the cost and processing benefits obtainable through the Spraycast- $X^{\circledR}$ process, a decision has been made to build a larger facility than the one currently available at Howmet Corporation. The current facility is capable of spraying approximately 850 pounds of product with a maximum diameter of 30 inches. The new unit, currently under construction, will have the capability of spraying up to 6000 pounds of alloy with a maximum diameter of 55 inches. Both of these units are configured principally for the production of ring shaped components such as engine cases and other circularly symmetric components for gas turbine engines.

\section{Spraycast- $X^{\otimes}$ Process Overview}

In 1987, Howmet Corporation, an industry leader in the production of gas turbine components for aerospace and industrial engines, licensed the Osprey process ${ }^{(2-4)}$ from Osprey Metals, Ltd. (UK), to produce nickel-based alloys for gas turbine engine applications. Over the past 2-3 years, however, major strides have been made in processing alloys such as IN718 into jet engine ring and case shapes. The Spraycast- $X^{\circledR}$ process builds on the Osprey process know-how, but in addition, incorporates vacuum melting and processing technology. Spraycast- $X^{(B)}$ is a onestep conversion of molten alloy to a fine grain, homogeneous ring (or case) preform, having an as-sprayed density of $\sim 98 \%$. Figure 1 is a schematic of the Spraycast- $X^{\circledR}$ process. The process consists of vacuum induction melting (VIM) the desired alloy in a ceramic crucible, delivering this alloy to a tundish and metering the alloy from the tundish through a controlled orifice (nozzle). This metered alloy stream is then passed through the Osprey Metals, Ltd. two-stage atomizer array; within which the stream is broken up by high purity argon gas impingement, into a 
spray. This spray is then deposited onto a preheated mild steel mandrel which rotates under the spray. The desired shape and thickness of the deposit is controlled by the withdrawal of this mandrel from under the spray plume. This resultant preform can then be used either in the hot isostatically pressed (HIP) only, HIP + ring rolled, HIP + forged, etc. form, as desired by the customer. A map of the thermo-mechanical processing options can be seen in Figure 2. Although the assprayed density of the deposited material is quite high (i.e., 98\%), HIP is required to close all remaining porosity; therefore, HIP is an integral process step to the Spraycast- $X^{\circledR}$ process.
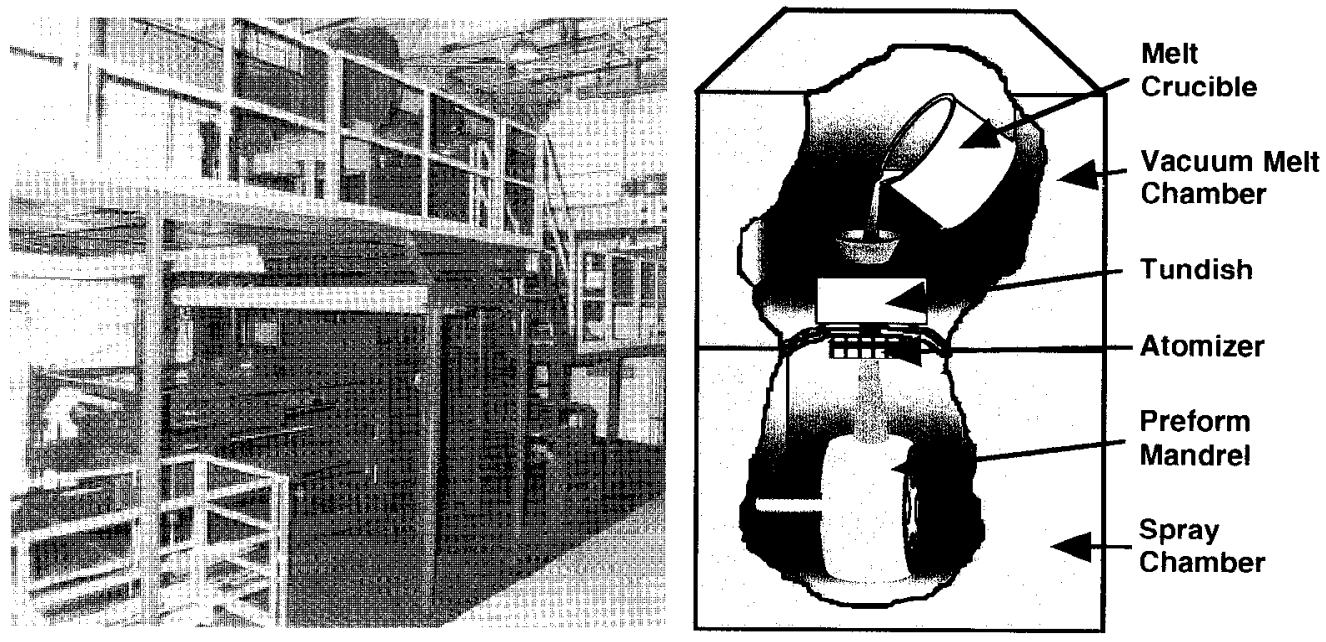

Figure 1 - Spraycast- $X^{(B)}$ Furnace and Schematic.

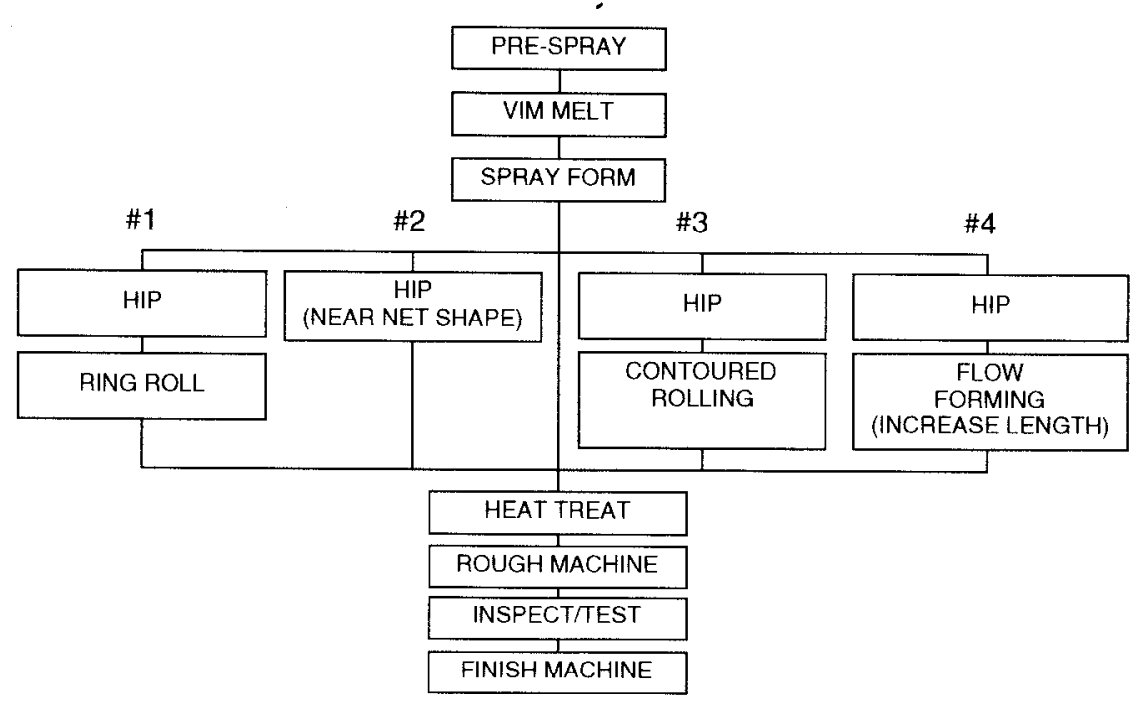

Figure 2 - Thermomechanical Processing Options.

The current Howmet pilot production facility has an 850 pound melt capacity of superalloy remelt stock, and delivers this alloy to the atomizer at a rate of up to 100 pounds per minute. The metal stream is broken up by a standard Osprey atomizer 
with an attendant flow rate of up to 950 cubic feet per minute. Typically, $80 \%$ of the sprayed material sticks on the mandrel and attendant deposit. The resultant $20 \%$ of alloy which does not stick is captured in the form of powder or flakes. With proper inert collection techniques, this powder/flake overspray material can be directly remelted for use in the next spray campaign.

A third generation Spraycast- $X^{\circledR}$ production unit is to be built by Howmet and to be operational in 1998. This unit is being built to manufacture singular or multiple ring and case parts up to $60^{\prime \prime}$ long $\times 55^{\prime \prime}$ in diameter. This facility will have an approximate melt capacity of 6000 pounds. This unit will have the capability to capture and handle the overspray powder for direct remelting, and will have 4 axis motion to articulate the mandrel under the spray plume.

Vacuum processing allows for the melting of alloys, like IN718 with reactive alloy additions, without the restriction imposed due to the segregation concerns of conventional ingot melting. It is quite typical to have dissolved oxygen levels of $<10$ $\mathrm{ppm}$, and nitrogen levels $<60 \mathrm{ppm}$ for IN718 alloy processed by the Spraycast- $X^{\circledR}$ method. The as-sprayed material is extremely homogeneous, and exhibits a uniform grain size which is predominately dictated by the alloy composition. The resultant spray + HIP grain size for IN718 is in the ASTM 5-7 range as shown in Figure 3.

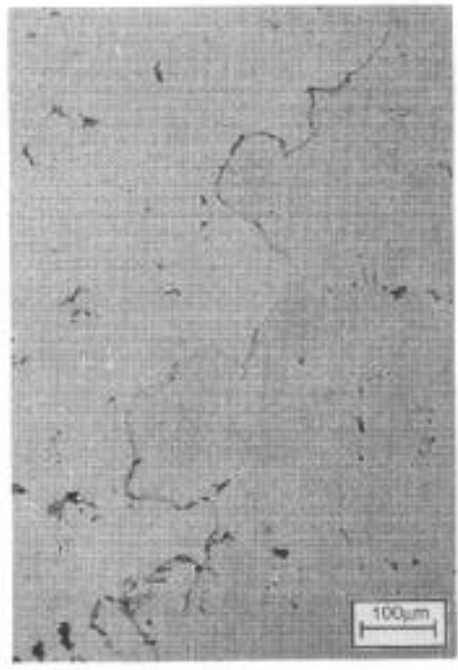

Conventional Cast $2050^{\circ} \mathrm{F}$ HIP

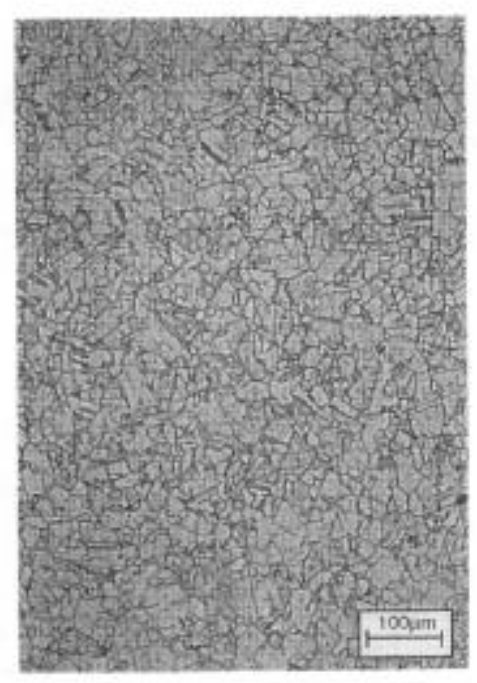

Cast + Wrought

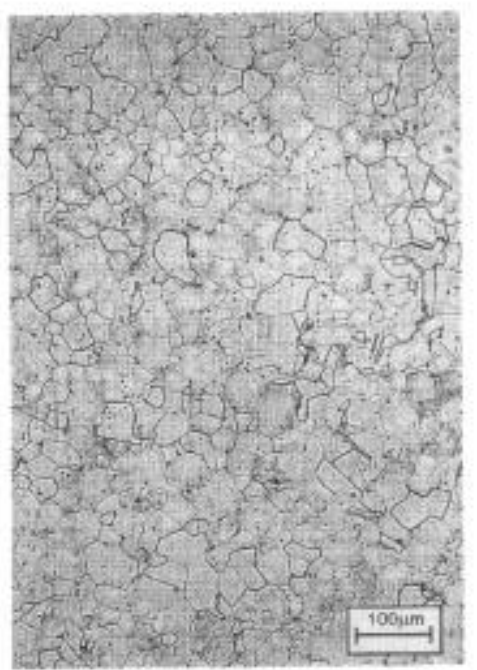

Spraycast- $X^{\circ}+$ $1875^{\circ} \mathrm{F} \mathrm{HIP}$

Figure 3 - IN718 Microstructure Comparison.

Both the conventional Osprey and early Spraycast- $X^{\text {p }}$ process efforts needed technological breakthroughs to overcome barriers to production of ring and case components. Some of these barriers were: 1) development of a simple spray routine for thick wall $\left(\sim 3^{\prime \prime}\right)$ ring and case components; and 2) elimination of internal diameter (ID) fissure porosity. 


\section{Scanning Single Pass Spray Routine}

Howmet developed a single pass spray routine within which the required thickness on the rotating mandrel is built up by withdrawing the mandrel from underneath the spray plume unidirectionally in one continuous motion. As the mandrel is withdrawn, the Osprey atomizer is scanned over specified angles to spread the alloy over a discrete surface of the mandrel. The scanning routine is programmed so as to overlap the normal spray distributions, thereby resulting in a uniform build up of metal on the mandrel. The withdrawal rate of the mandrel is set to give the prescribed deposit thickness at precise areas on the mandrel. This spray routine is easily tailored from one substrate shape and size to another, with minimal calculation and programming.

\section{ID Fissure Porosity Elimination}

In the past, the single pass process was thought to be non-viable as a spray technique because of the large amount of non-HIP surface connected ID porosity which was left just above the OD of the mild steel mandrel. Over the years, many sources have witnessed up to $50 \%$ of the deposit thickness affected by the ID fissure porosity.

The first innovation was to preheat the mild steel mandrel. The preheating helped assure that the first alloy onto the mandrel was firmly stuck. Keeping this depositto-mandrel interface hot aided in reducing the ID fissure porosity.

The second innovation was to increase the mass flux through the atomizer nozzle, i.e., increase the metal flow rate. In previous billet work, the objective was to maintain a very fine ( ASTM 10 or finer) microstructure. However, the operating conditions of case and ring components (high temperature and pressure) require somewhat coarser grain sizes (e.g., ASTM 5-7). To some extent, increasing the mass flux of alloy will coarsen the grain size somewhat, although the grain size is determined by nucleation ${ }^{(5)}$. In addition to coarsening the grain size, a higher mass flux also increases the temperature of the "fringe" areas of the spray. Increasing these fringe temperatures helps to remelt any ID fissure areas at the deposit-tomandrel interface. Therefore, increasing the mass flux to the process reduces the ID fissure porosity amount.

\section{Generic Spraycast- $X^{\circledR}$ Ring and Case Characteristics}

The Spraycast- $X^{\circledR}$ process offers many unique technical and economic advantages as compared to conventional castings, cast + wrought product, or powder metallurgy parts. By virtue of its vacuum melting and processing, the Spraycast- $X^{\circledR}$ product is extremely clean (Figure 4: Spraycast- $X^{\circledR}$ Process Cleanliness), as compared to conventional remelt stock. Also the rapid solidification process results in a product with minimum segregation. Spraycast- $X^{\circledR}$ processed material allows the customer some flexibility in determining the post spray + HIP processing route. For static components, the customer may choose to use the spray + HIP preform directly for component manufacture. However, for rotating rings, where hot working is currently a requirement, the spray + HIP product may be directly ring rolled or 
forged as necessary. Since the Spraycast- $X^{\boxplus}$ process uses VIM remelt stock, the turn time from placement of order to spray + HIP of the component is extremely short; usually measured in days or weeks. This quick delivery is stark contrast to the conventional alloy mill turn time for cast + wrought billet material, which can run from many months to $\sim 1$ year.

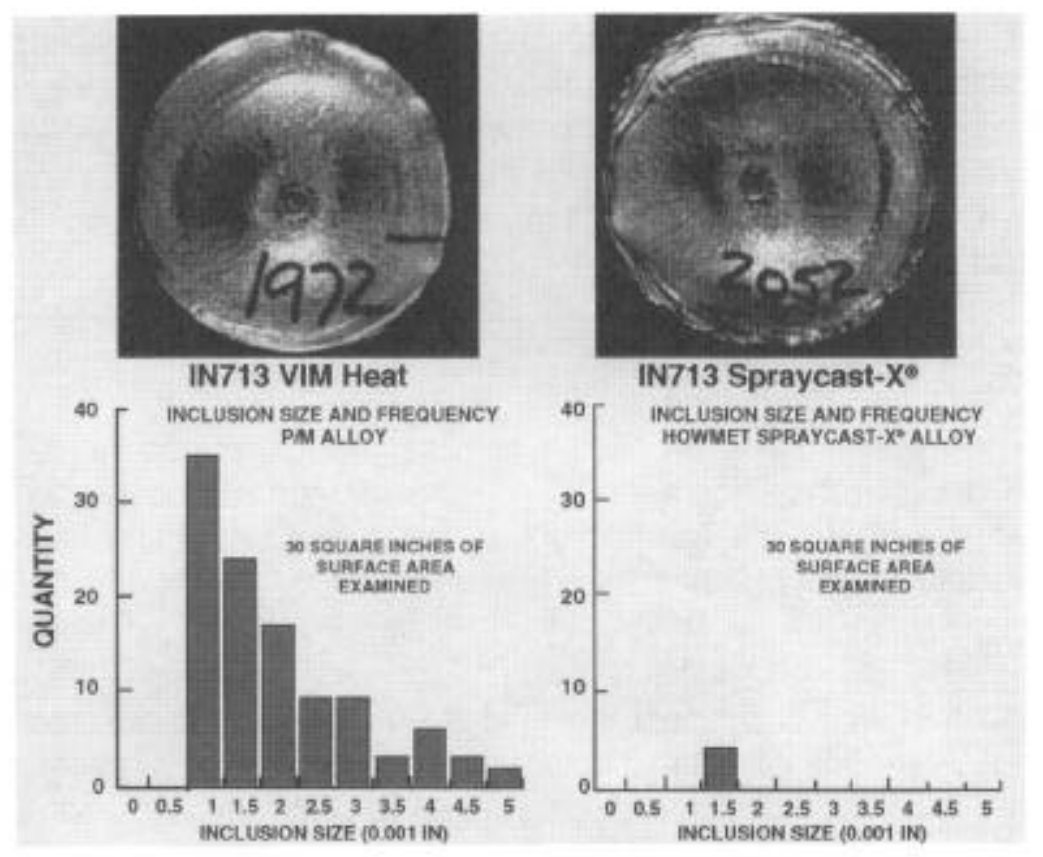

Figure 4 - Spraycast- $X^{\circledR}$ Process Cleanliness.

In addition to the technical and turn time improvement of Spraycast- $X^{\circ}$ parts; an economic comparison of argon atomized Spraycast- $X^{\otimes}$ product to typical cast + wrought and $\mathrm{P} / \mathrm{M}$ commodities shows Spraycast- $X$ to offer substantial savings (Table I: Generic Cost Comparisons of Spraycast $-X^{\circledast}$ vs. Cast + Wrought and P/M Process).

Table I Cost Comparison of Spraycast- $X^{\circledR}$ vs. Cast+Wrought and P/M Process.

\begin{tabular}{|l|l|l|l|}
\hline & Cast+Wrought & Spraycast- $\mathrm{X}^{\circ}$ & P/M Process \\
\hline $\begin{array}{l}\text { Relative } \\
\text { raw materials usage }\end{array}$ & $100 \%$ & $70 \%$ & $100 \%$ \\
\hline Lead time & $12-16$ weeks & $2-4$ weeks & $12-16$ weeks \\
\hline Labor & $100 \%$ & $80 \%$ & $100 \%$ \\
\hline $\begin{array}{l}\text { Relative } \\
\text { finish machining costs }\end{array}$ & $100 \%$ & $65-80 \%$ & $100 \%$ \\
\hline Net savings & - & up to $30 \%$ & - \\
\hline
\end{tabular}


Usage of Spraycast- $X^{\circledR}$ product in the spray + HIP form also circumvents many of the up front processing steps traditionally performed at ring roll operations (Figure 5 shows ring roll steps eliminated with Spraycast- $X^{\mathbb{B}}$ ). Both qualitative and quantitative information have been obtained from ring roll sources which indicate that the spray + HIP preforms are easier to ring roll, as compared to their cast + wrought counterparts of the same alloy. Although this is true for the IN718 alloy, this improved hot working characteristic takes on even more value in the more "non-hot workable" alloy systems (e.g., Waspaloy, U720, etc.). Much of the improved hot workability afforded by the Spraycast- $X^{\circledR}$ process comes, in part, from the improved flow stress (compared to cast + wrought) (Figure 6: Wrought vs. Spraycast- $X^{\circledR}$ Flow Characteristics), which is a result of the improved homogeneity and uniformity of the Spraycast- $X^{\circledR}$ microstructure.
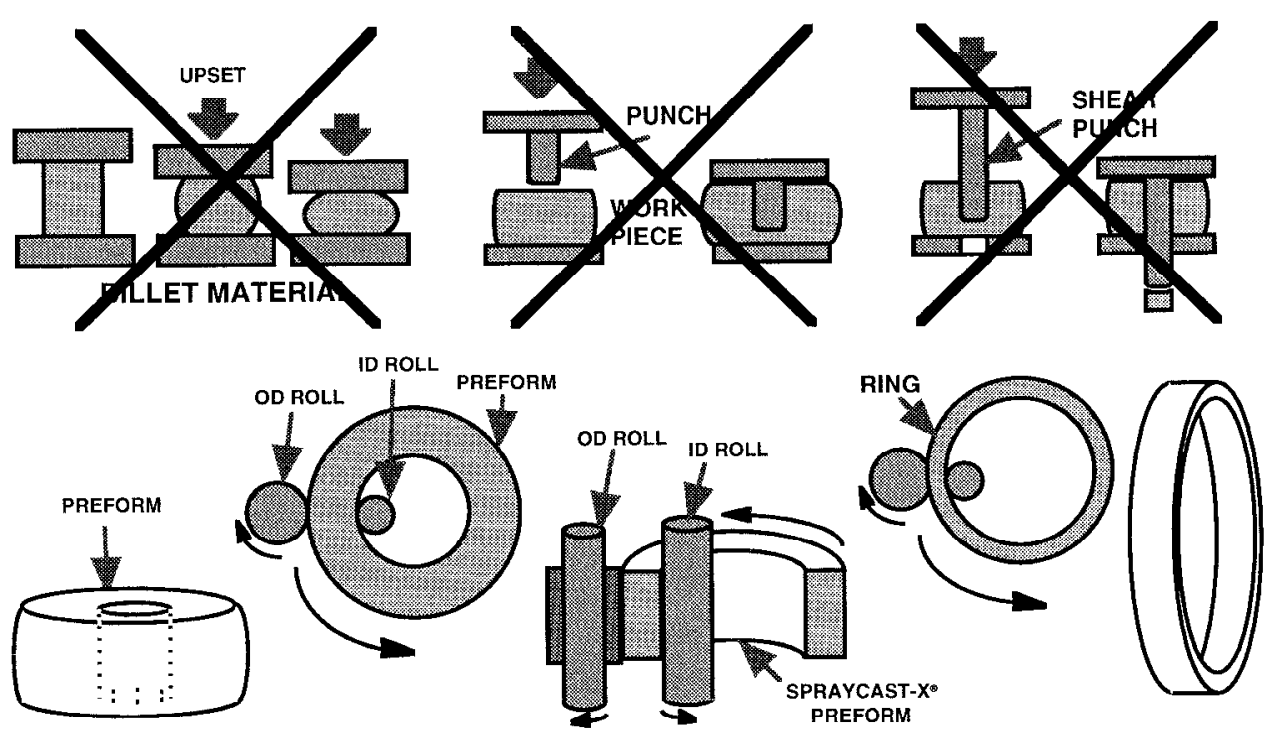

Figure 5 - Seamless Rolled Ring Forging Process.

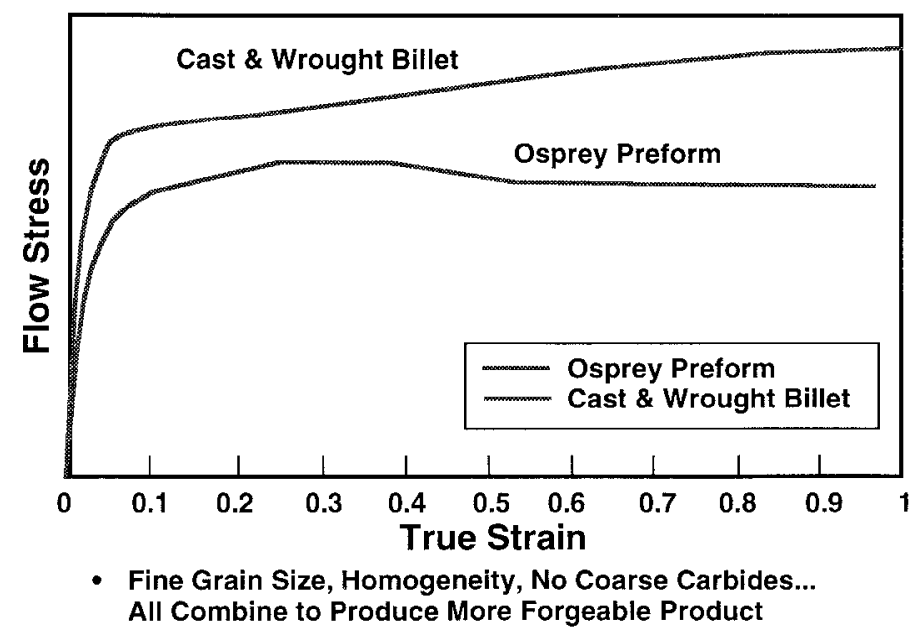

Figure 6 - Wrought vs. Spraycast- $X^{\circledR}$ Flow Characteristics. 
One of the most costly items in the manufacture of jet engine cases and rings is the final machining detail which must be added to the component for bolt patterns, instrumentation pass-throughs, etc. (Figure 7: PW4000 Turbine Case). An independent laboratory has performed a machinability evaluation comparing similar chemistries of cast + wrought U720 to Spraycast $X^{\circledR}$ spray + HIP U720, both given identical heat treatments. The results of these tests (Figure 8: U720 Machinability Study Spraycast- $X^{\circledR}$ vs. Cast + Wrought) show the Spraycast- $\left.X^{(}\right)$material to have a $35 \%$ improvement in cutting speed with an attendant two order of magnitude improvement in tool life. Qualitative information from other Spraycast- $X^{\circledR}$ customers also indicates that the same 25 to $35 \%$ cutting speed improvement has also been seen in the IN718 and Waspaloy alloys. Examination of the cast + wrought vs. Spraycast- $X^{\circledR}$ U720 microstructures shows that large primary carbides remain in the cast + wrought material, but these are not evident in the Spraycast- ${ }^{\circledR}$ form (Figure 9: Comparison of Wrought to Spraycast- $X^{\circledR}$ U720 SEM Micros). Again, the homogeneity and grain size uniformity afforded by the Spraycast- $X^{\circledR}$ process improve the machinability of typical aerospace alloys, without any chemistry or heat treatment modifications.

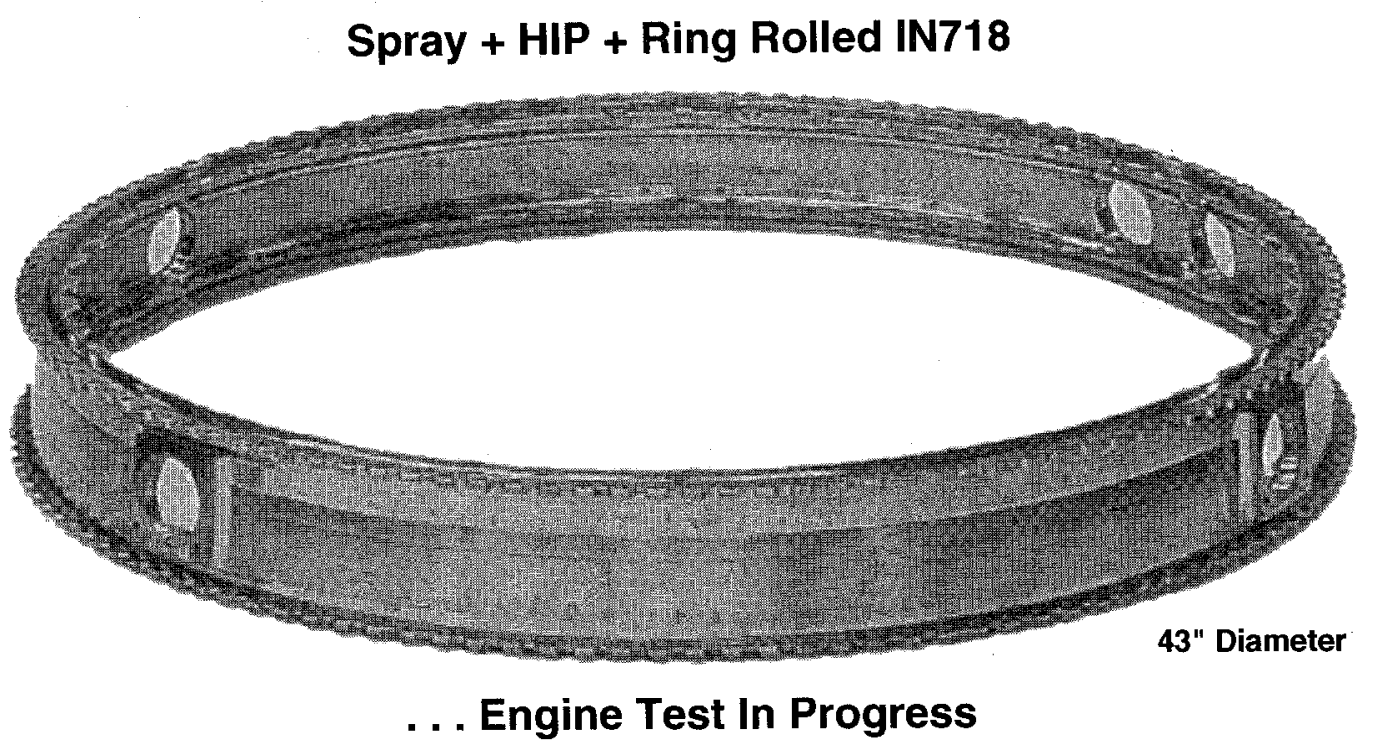

Figure 7 - PW4000 Turbine Case.

"Marked improvements" in ultrasonic inspectability of Spraycast- $X^{\circledR}$ material, as compared to conventionally processed forms (e.g., cast + wrought, P/M, etc.) have been reported. It is believed that the improved homogeneity and microstructural uniformity the critical process attributes are responsible for improved inspectability.

Figure 10 shows the typical tooling used for making components by the Spraycast$X^{\mathbb{B}}$ process. This tooling is simply mild steel tooling (mandrel) which is either spin formed (for production runs) or hand fabricated and welded (for 1st article or development parts). In either case, the mild steel mandrel is quite inexpensive compared to the cost of the overall component. After fabrication, this mandrel is aggressively grit blasted to make a rough surface. The ability of the spray material to stick to the mandrel is in part assured by the mandrel's roughness; the other 
component necessary for the alloy to stick being a "hot" mandrel surface (i.e., $>1400^{\circ} \mathrm{F}$ ). As a result of this inexpensive and quick mandrel technique, in tandem with the one step conversion of alloy, the Spraycast- $X^{\mathbb{B}}$ process is well situated to react to rapid prototype part orders. For instance, the Spraycast- $X^{10}$ process has been used to deliver two engine exhaust cases from print to spray + HIP parts in 6 days.
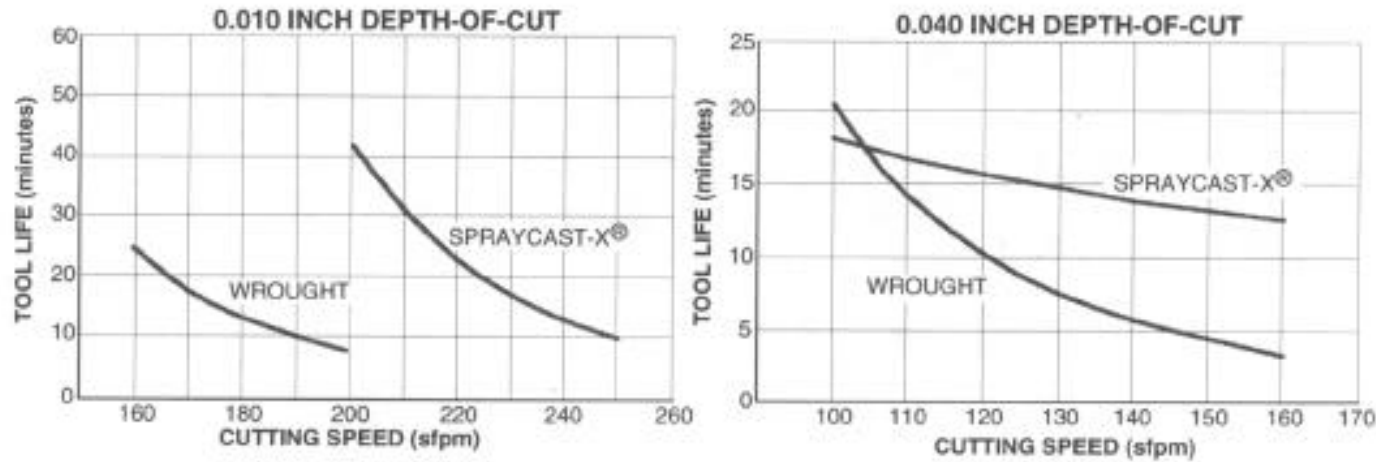

\section{Spraycast-X® U720}

- $35 \%$ Higher Cutting Speeds

- Longer Tool Life

- $263 \%$ at $0.040^{\prime \prime}$ Depth-ot-Cut / 160 SCFM Cutting Speed

- $465 \%$ at $0.010^{*}$ Depth-of-Cut / 200 SCFM Cutting Speed

- Significant Machining Cost Savings

Figure 8 - U720 Machinability Study: Spraycast- $X^{2}$ vs. Cast+Wrought.

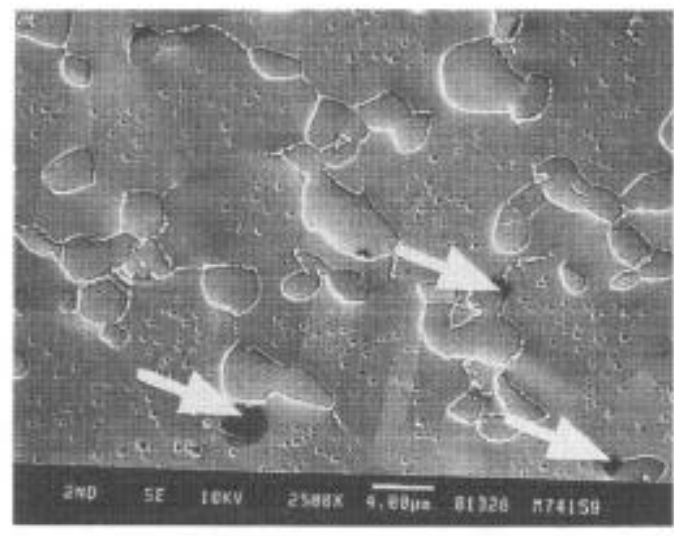

U720 Cast+Wrought

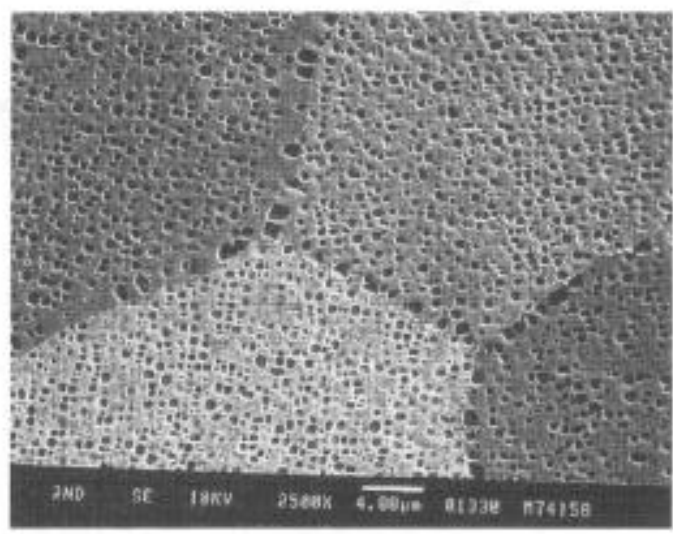

U720 Spraycast- $\mathrm{X}^{\star}+\mathrm{HIP}$

(Arrows Denote MC Carbides)

Figure 9 - Scanning Electron Microscope (SEM) Comparison of Wrought vs. Spraycast- $X 720$. 


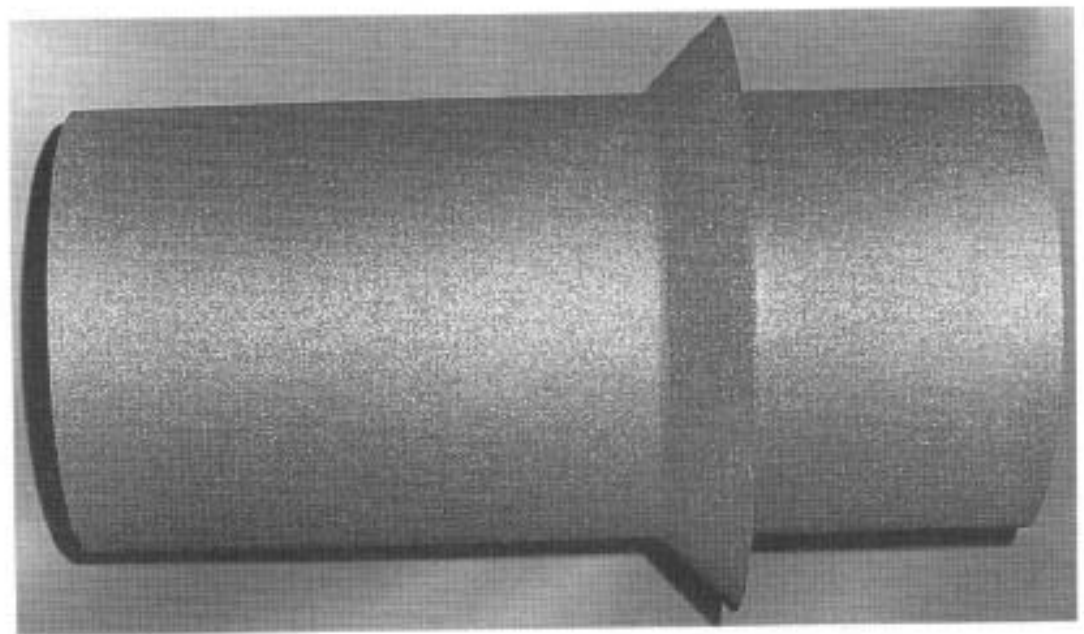

Figure 10 - Typical Tooling (Mandrel) for Spraycast- $X^{\bullet}$ Process.

\section{Spray + HIP and Spray + HIP + Ring Rolled Inconel 718 Evaluation Details}

Four (4) 500 pound IN718 cylindrical shapes were spray formed and consolidated by hot Isostatic pressing (HIP) at $1875^{\circ} \mathrm{F} / 29 \mathrm{ksi} / 3 \mathrm{hrs}$. Two of the ring shapes were heat treated directly following HIP, in the absence of any thermomechanical processing, and destructively tested (tensile, creep/rupture, low cycle fatigue, and fatigue crack growth). The two other rings were spray formed and HIP'ed as described above, rough machined into ring roll preform shapes, and delivered to Viking Metallurgical Corporation, where they were finish rolled into PW4000 high pressure turbine (HPT) case shapes and heat treated. One of the rolled rings underwent the same level of destructive testing as for the direct spray + HIP shapes described above, while the other rolled ring was finish machined into a production PW4000 high pressure turbine (HPT) case at Pratt and Whitney and engine tested.

\section{Results}

Chemical compositions of both the spray + HIP and spray + HIP + ring rolled case shapes met standard cast + wrought IN718 (AMS 5663) specification requirements (Table II). All of the case shapes exhibited a segregation-free, uniform ASTM 6-7 grain structure, and delta phase precipitated as short needles at the grain boundaries (Figure 11). Exhaustive examination of multiple locations revealed that no grains larger than ASTM 5 were found in any of the four rings. Furthermore, blocky MC carbides, which are typically found in conventional cast + wrought IN718, were not found.

\section{Spray + HIP IN718 Heat Treatment Development}

A heat treatment study was performed on spray + HIP IN718 in order to optimize the mechanical properties of this unique product form. Testing showed that spray + HIP IN718 processed per a new Pratt \& Whitney-developed heat treatment cycle results ${ }^{(6)}$ in improved stress rupture life and comparable strength relative to spray + 
HIP material processed per the standard AMS 5663 heat treatment cycle. This heat treatment was thus imparted to the two spray + HIP ring shapes used in this study. Conversely, the two spray + HIP + ring rolled IN718 rings in this study were heat treated per the standard IN718 (AMS 5663 specification) cycle.

Table II Chemical Compositions of Inconel 718 (IN718) Product Forms.

\begin{tabular}{cccc} 
Element & $\begin{array}{c}\text { AMS } 5663 \\
\text { Specification }\end{array}$ & Spray+HIP & $\begin{array}{c}\text { Spray+HIP+ } \\
\text { Ring Rolled }\end{array}$ \\
\hline $\mathrm{C}$ & 0.08 max & 0.05 & 0.05 \\
$\mathrm{Mn}$ & 0.35 max & 0.02 & 0.02 \\
$\mathrm{Si}$ & 0.35 max & 0.09 & 0.08 \\
$\mathrm{P}$ & $0.015 \mathrm{max}$ & 0.007 & 0.007 \\
$\mathrm{~S}$ & $0.015 \max$ & 0.002 & 0.003 \\
$\mathrm{Cr}$ & $17.00-21.00$ & 18.75 & 18.99 \\
$\mathrm{Ni}$ & $50.00-55.00$ & 52.29 & 52.73 \\
$\mathrm{Mo}$ & $2.80-3.30$ & 2.99 & 3.05 \\
$\mathrm{Nb}$ & $4.75-5.50$ & 5.23 & 4.89 \\
$\mathrm{Ti}$ & $0.65-1.15$ & 0.86 & 0.89 \\
$\mathrm{Al}$ & $0.20-0.80$ & 0.49 & 0.55 \\
$\mathrm{Co}$ & 1.00 max & 0.25 & 0.26 \\
$\mathrm{~B}$ & 0.006 max & 0.004 & 0.005 \\
$\mathrm{Cu}$ & 0.30 max & 0.01 & 0.02 \\
$\mathrm{~Pb}$ & $5 \mathrm{ppm}$ max & $1 \mathrm{ppm}$ & $<5 \mathrm{ppm}$ \\
$\mathrm{Bi}$ & $0.3 \mathrm{ppm}$ max & $<0.03 \mathrm{ppm}$ & $<0.3 \mathrm{ppm}$ \\
$\mathrm{Se}$ & $3 \mathrm{ppm}$ max & $<1 \mathrm{ppm}$ & $<3 \mathrm{ppm}$ \\
$\mathrm{Fe}$ & remainder & remainder & remainder
\end{tabular}

\section{Mechanical Property Results}

Figure 12 illustrates tensile strength results obtained for both spray + HIP and spray + HIP + ring rolled IN718 relative to conventional cast + wrought IN718. Both product forms exhibited $0.2 \%$ yield and ultimate strength values within $5 \%$ of wrought IN718 typical values. Strength was insensitive to test direction, underscoring the uniformity of the spray formed product.

Smooth stress rupture results are shown in Figure 13. Both spray + HIP and spray + HIP + ring rolled IN718 were found to be equivalent to cast + wrought IN718 in rupture life.

Fully reversed, smooth low cycle fatigue testing (Figure 14) showed that spray + HIP IN718 (ASTM grain size 5.5 to 6.5) failure lives were comparable to, or slightly better than, those for cast + wrought IN718 (ASTM grain size 8). This is attributed to the cleanliness and finer carbide distribution of Spraycast- $X^{\circledR}$ processed material. Similar LCF results have been reported by D. Bryant et al. ${ }^{(7)}$ for Spraycast- $X^{\circledR}$ U720. Fractographic and semi-quantitative (KEVEX) analysis of initiation sites revealed clean-looking cleavage facets at specimen origins. No evidence of coarse MC carbides or melt-related defects were found at any of the origins examined.

Hold time fatigue crack growth testing at $1100^{\circ} \mathrm{F}$ (Figure 15) showed that results were generally comparable to results obtained using cast + wrought IN718. Fractographic and metallographic examination revealed that all of the crack growth specimens exhibited relatively tortuous, mixed mode fracture paths and extensive secondary cracking. 

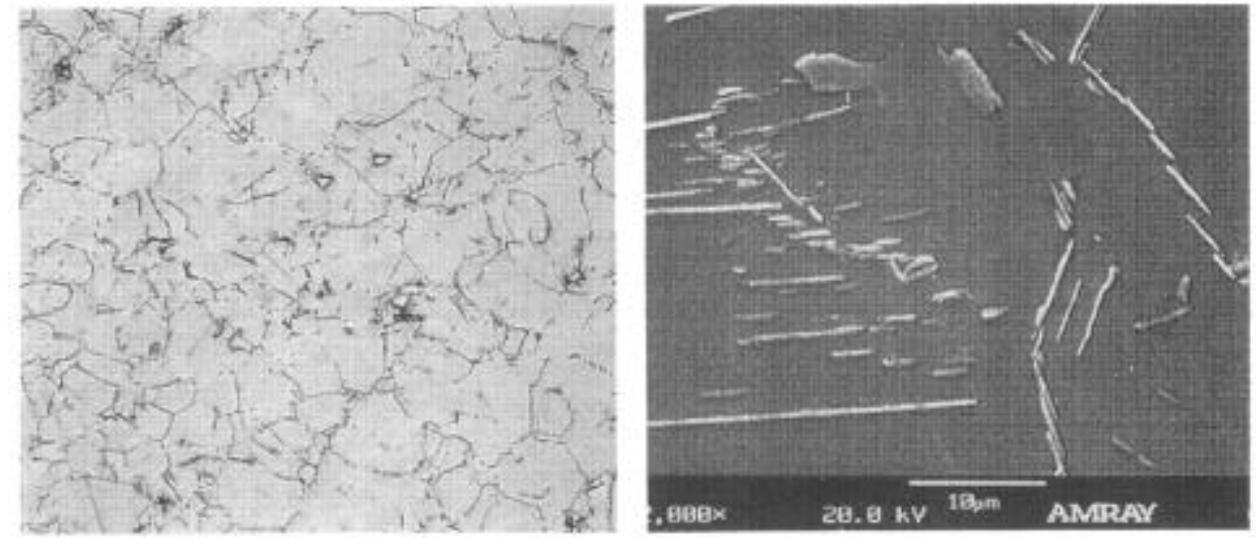

(a)
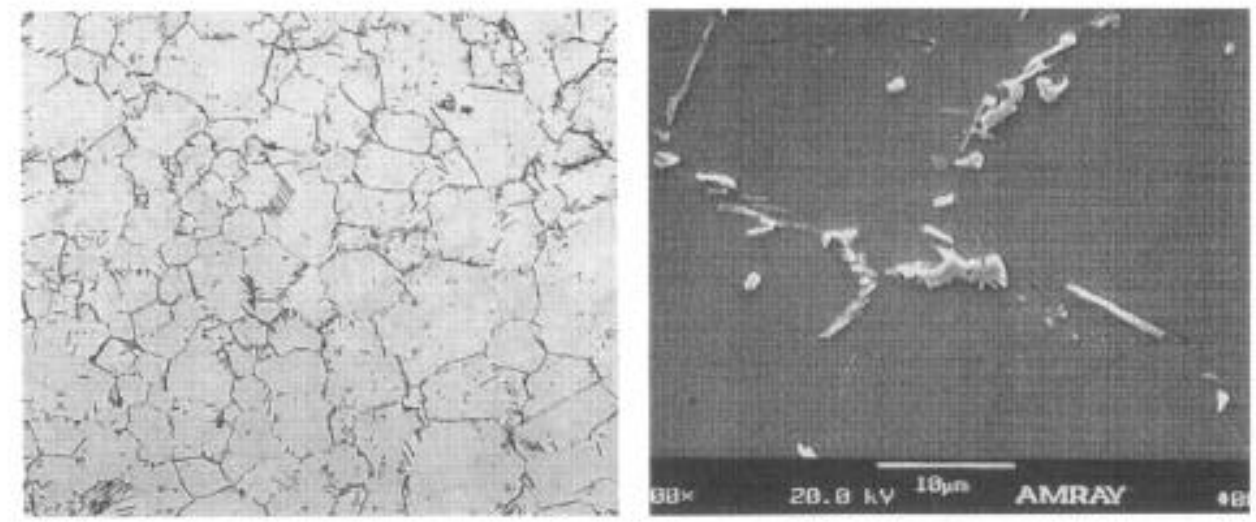

(b)
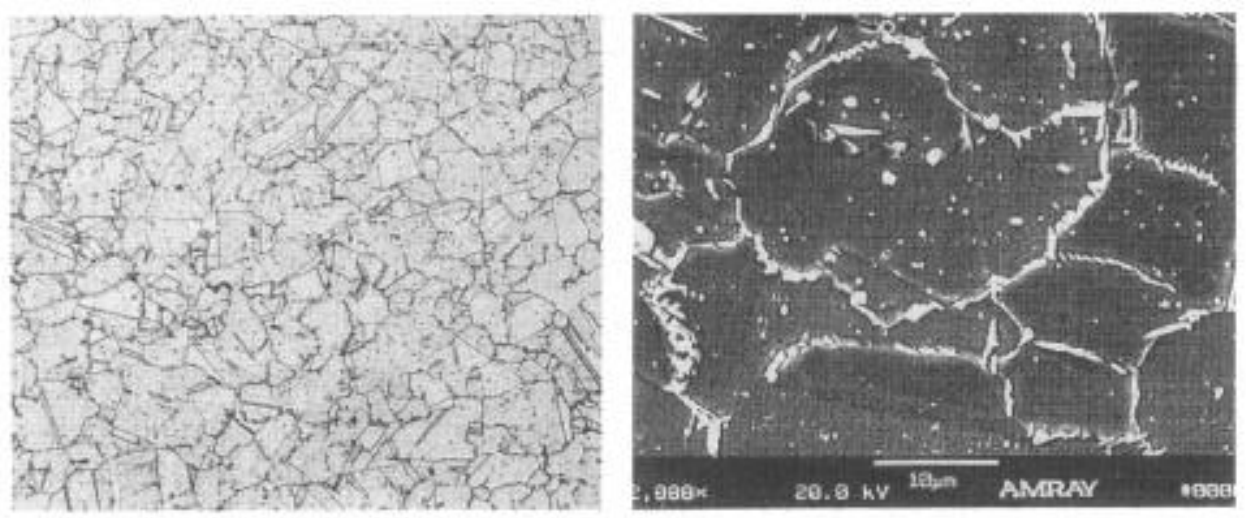

(c)

Figure 11 - Typical IN718 Microstructures: (a) Conventionally Cast+Wrought, (b) Spray+HIP, and (c) Spray+HIP+Ring Rolled. 


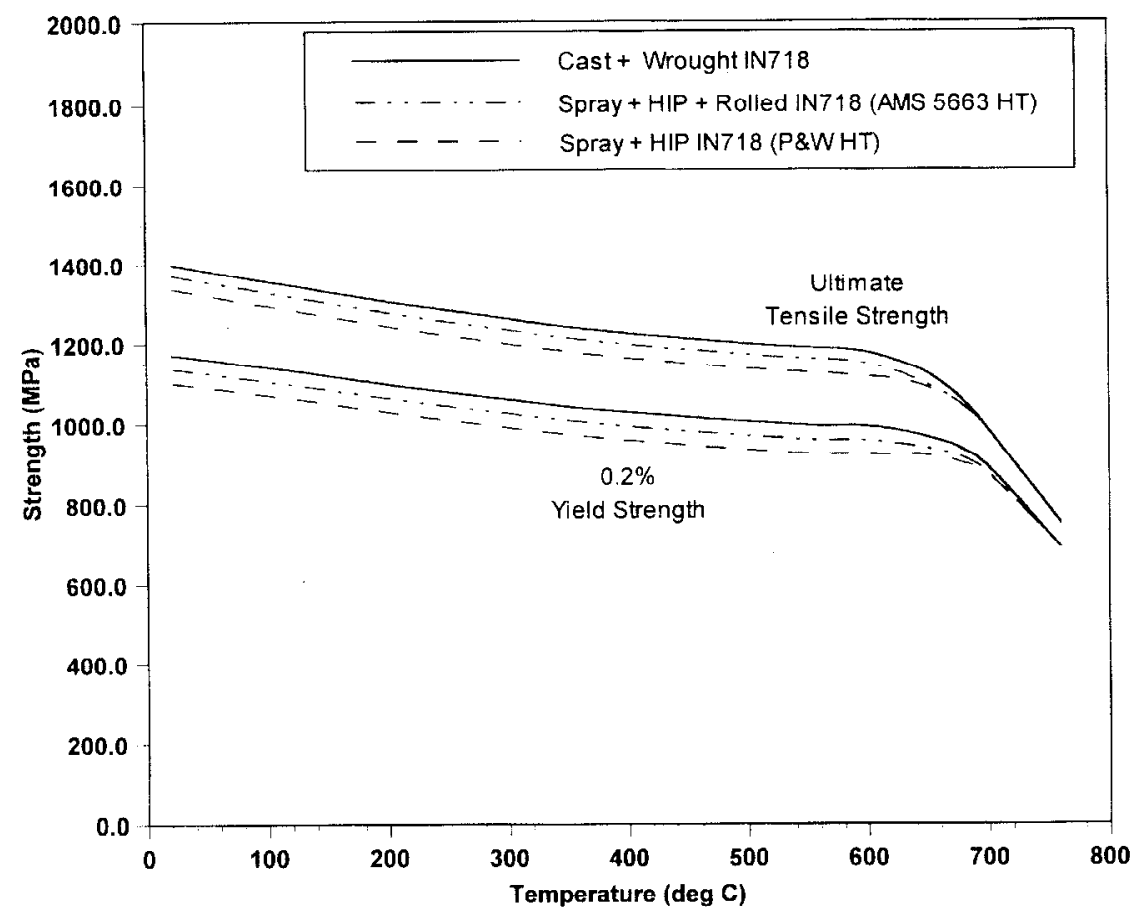

Figure 12 - Spraycast- $X^{\circledR}$ IN718 Tensile Results.



Figure 13 - Spraycast- $X^{\circledR}$ IN718 Stress Rupture Results. 


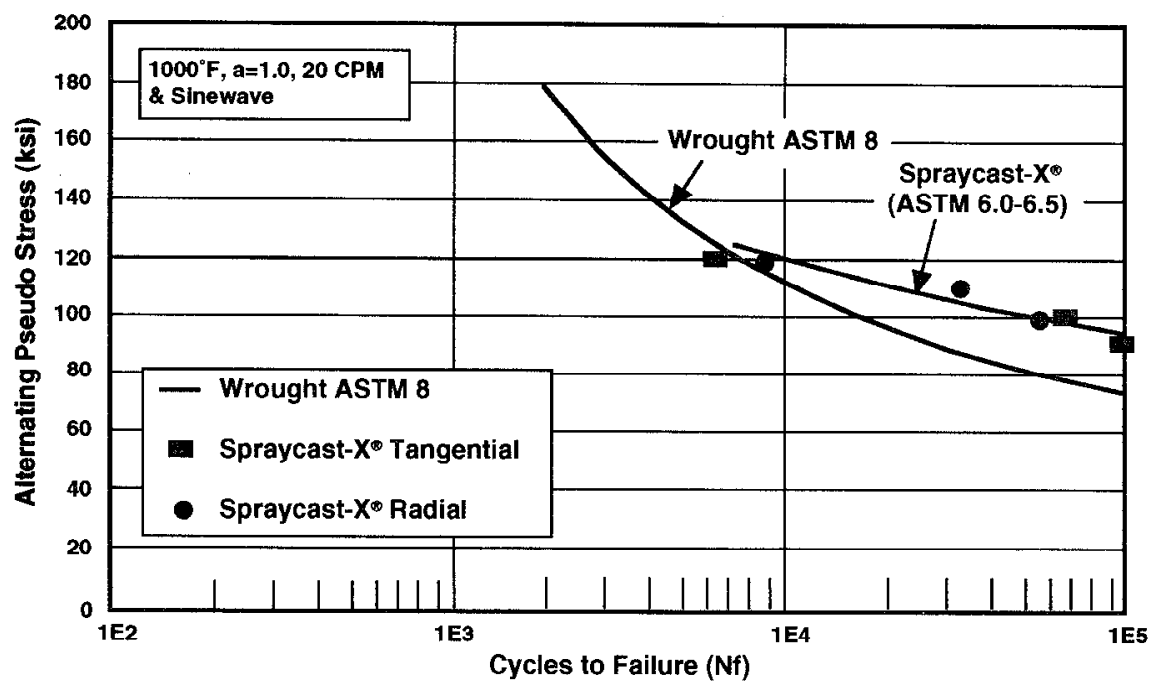

Figure 14 - Spraycast- $X^{(\circledast)}$ IN718 Low Cycle Fatigue Properties.

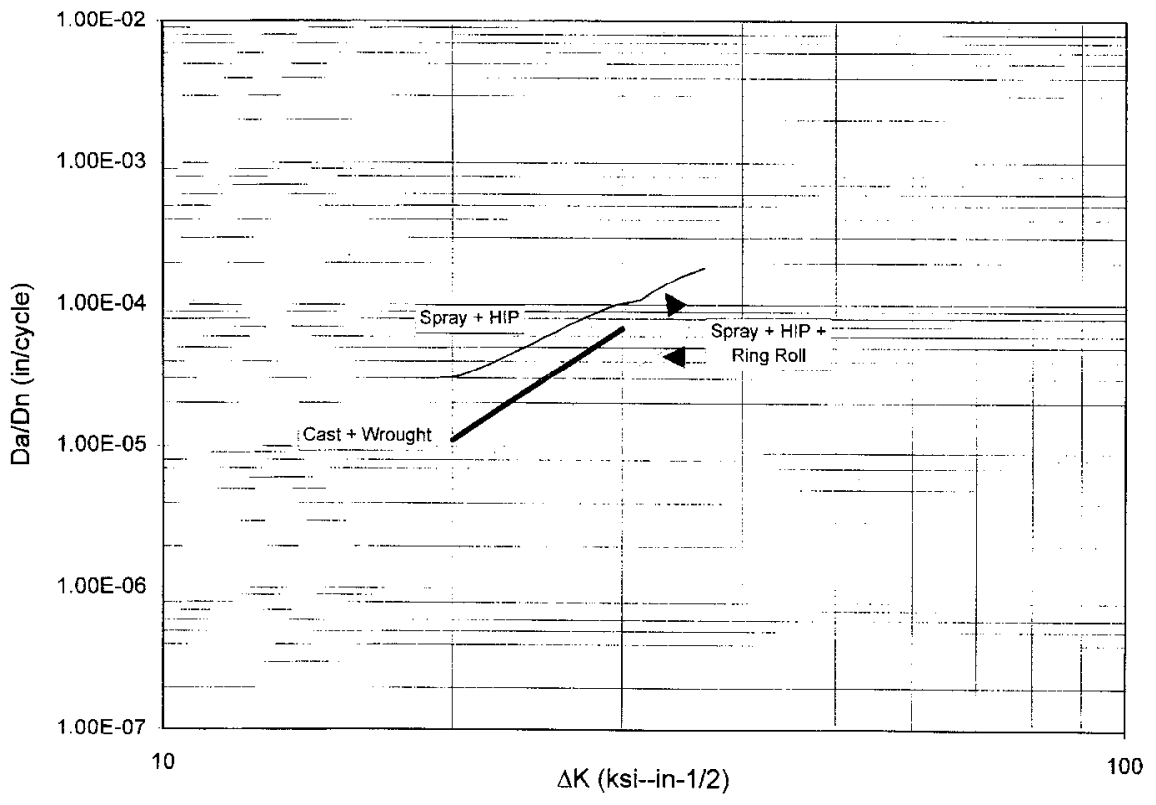

Figure $15-1100^{\circ} \mathrm{F}$ Fatigue Crack Growth Results.

\section{Engine Testing Experience}

A PW4000 high pressure turbine (HPT) case was machined using one of the spray + HIP + ring rolled shapes. Figures 16 and 7 illustrate the evolution of this case from (a) sprayed shape to (b) ring rolled and (c) rough machined condition to (d) finish machined case. Viking reported ${ }^{(8)}$ that the two spray + HIP preform shapes exhibited improved forgeability and reduced edge cracking relative to the production cases made from standard cast + wrought IN718 billet which was rolled during the same campaign. It is believed that this was due to the inherently more uniform, finer grain structure and absence of coarse MC carbides in the spray + HIP ring preform relative to conventional IN718 billet. In addition, Pratt \& Whitney, 
Manufacturing reported that the fine grained, coarse MC carbide-free spray + HIP + rolled ring exhibited improved machinability over conventional cast + wrought IN718 throughout the manufacturing cycle of the HPT case. Specifically, it was reported that a reduced number of tools were used to drill the case's holes.
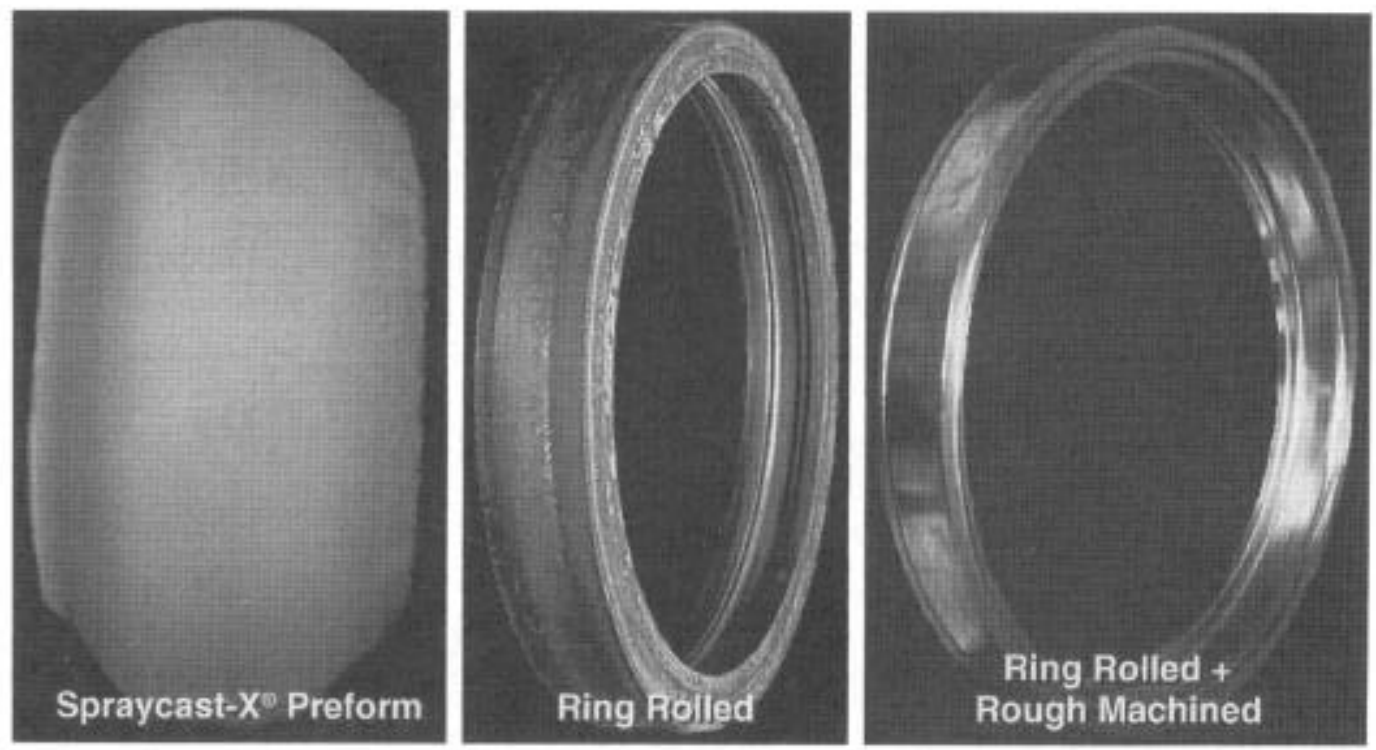

Figure 16 - Spraycast- $X^{\circledR}$ IN718 High Pressure Turbine Case.

Specification tensile and stress rupture test results from the second spray + HIP + rolled ring were similar to the results obtained from the destructively-tested ring. Non-destructive (ultrasonic) inspection of this ring prior to final case machining revealed no indications, even when inspected to a \#2 flat bottom hole (FBH) sensitivity level, a standard twice as stringent than what is required for conventional cast + wrought IN718.

This case has been operating successfully in a Pratt \& Whitney experimental engine for approximately 1000 hot endurance cycles. Visual examination of the case between engine builds ( 500 cycles) revealed no evidence of distress.

\section{Conclusions}

An enhanced Osprey process through the use of vacuum melting and process technology to produce aerospace quality nickel-based superalloy ring/case preforms has been demonstrated in a pilot facility. The main advantage of the Spraycast- $X$ process is the reduced cost; other advantages include reduced lead time, improved machinability, inspectability and alloy cleanliness. Microstructure and mechanical properties of both spray + HIP and spray + HIP + ring rolled IN718 were comparable to conventional cast + wrought IN718. A spray + HIP + ring rolled IN718 PW4000 high pressure turbine (HPT) case has been successfully engine tested. The pilot facility will be upgraded in 1997 to increase output from 100,000 lbs. to $500,000 \mathrm{lbs}$. In 1998 , the $6000 \mathrm{lb}$. production facility will be on line with a $1,000,000 \mathrm{lbs}$./shift per year capacity. 


\section{Acknowledgments}

The authors thank Howmet Corporation and Pratt and Whitney for permission to publish this work. The authors wish to thank our team members Dave Cook and Dave Ingersoll who spray formed the material, Ralph Giugno and Sue Goetschius for the microstructural and data analysis, respectively, of the spray formed rings, Jack Schirra for timely and insightful metallurgical discussions, and Doug Polter for providing the liaison between Howmet and Pratt and Whitney.

\section{References}

1. Leatham, A.G. et al., 1991, "The Past, Present and Future Developments of the Osprey Preform Process", Proceedings of the 1st Int'I. Conf. on Spray Forming, Swansea, UK; Osprey Metals, Ltd.

2. Osprey Metals, Ltd., UK, Patent No. 1379261.

3. Osprey Metals, Ltd., UK, Patent No. 1472939.

4. Leatham, A. G. and Brooks, R. G., 1984, "The Osprey Process for the Production of Spray Deposited Disc, Billet, and Tube Preforms", Modern Developments in Powder Metallurgy, 15, pp. 157-173.

5. Lavernia, E. J. and Wu, Y., Spray Atomization and Deposition, John Wiley \& Sons.

6. Pratt \& Whitney unpublished research.

7. Bryant, D., Rolls-Royce plc, Dalal, R., Howmet Corp., and Furrer, D., Ladish Co., Sept.1996, "Spraycast- $X^{\circledR}$ Process for Adv. High Strength Alloys for Ring/ Casing Components", Proceedings of the $3^{\text {rd }}$ Int'l. Conf. On Spray Forming, Cordiff, UK; Osprey Metals, Ltd.

8. Viking Metallurgical Corp. communication. 